\title{
Improvement of Bending Modulus and Impact Value in Injection-Molded Short Carbon Fiber Reinforced Polyetheretherketone with Homogeneous Low-Voltage Electron Beam Irradiation
}

\author{
Yoshitake Nishi ${ }^{1,2,3}$, Réda Ourahmoune ${ }^{1}$, Masae Kanda ${ }^{2}$, Junhua Quan $^{3}$, \\ Michael C. Faudree ${ }^{2}$ and Michelle Salvia ${ }^{1}$ \\ ${ }^{1}$ Ecole Centrale de Lyon, Ecully Cedex 69134, France \\ ${ }^{2}$ Department of Materials Science, School of Engineering, Tokai University, Hiratsuka 259-1292, Japan \\ ${ }^{3}$ Graduate School of Engineering, Tokai University, Hiratsuka 259-1292, Japan
}

In short carbon fiber reinforced polyetheretherketone (SCFRP-PEEK) composites, carbon fibers and PEEK matrix typically exhibit a weak adhesive force at the interface. However, applying $0.43 \mathrm{MGy}$ dose of homogeneous low-voltage electron beam irradiation (HLEBI) was apparently shown to improve not only the bending modulus $\left(E_{\mathrm{f}}\right) 65.5 \%$ at the median-ranked cumulative probability evaluated as a distribution function $\left(P_{\mathrm{E}}=0.50\right)$ from 6.7 to $11.1 \mathrm{GPa}$, but also Charpy impact fracture value $\left(a_{\mathrm{uc}}\right) 17.5 \%$ at median-ranked cumulative probability $\left(P_{\mathrm{f}}=0.50\right)$ from 16.6 to $19.5 \mathrm{~kJ} \mathrm{~m}^{-2}$. The $0.43 \mathrm{MGy}$ HLEBI dose also remarkably improved the statistically lowest Charpy impact value $a_{\mathrm{s}}$ at $P_{\mathrm{f}}=0$ calculated by 3 -parameter Weibull equation $80.0 \%$ from 8.0 to $14.4 \mathrm{~kJ} \mathrm{~m}^{-2}$. Penetration depth, $D_{\mathrm{p}}$ of the HLEBI was calculated to be 153 to $226 \mu \mathrm{m}(3-11 \%)$ into both side surfaces. SEM results of the HLEBI-treated Charpy impact sample fracture surfaces show more matrix sticking to the fibers and more matrix being held between fibers than the untreated increasing pullout resistance. The HLEBI appears to assist in strengthening the typically weak bonding between the carbon fiber and PEEK matrix improving mechanical properties. [doi:10.2320/matertrans.M2013455]

(Received December 19, 2013; Accepted May 7, 2014; Published June 20, 2014)

Keywords: carbon fiber reinforced polyetheretherketone (CFRP-PEEK), thermoplastic, short fiber, bending elasticity, impact, electron beam

\section{Introduction}

Carbon fiber reinforced polyetheretherketone (CFRPPEEK) thermoplastic polymers are typical composites applied as light structural materials with high strength for space, aircraft, automobiles and sports equipment. ${ }^{1,2)}$ Long fiber composites are fabricated by processes such as layup or resin transfer molding of unidirectional or woven plies, and filament winding. However, while short carbon fiber injection-molded SCFRP-PEEK does not offer the strength of the long fiber, it affords the ease, lower cost, and higher productivity rate $^{3)}$ on the many needed low- or non-loadbearing parts employed for prime mover applications as a stronger alternative to the short glass fiber reinforced polymer (SGFRP) composites.

With high maximum continuous working temperatures of $\sim 250^{\circ} \mathrm{C}^{4)}$ and superior corrosion resistance, ${ }^{5)}$ PEEK has been a state-of-the-art thermoplastic polymer. In addition to being able to easily fabricate parts using the various forming processes $^{3)}$ with strict tolerances and good repeatability in high volume production carbon fiber PEEK composites exhibit excellent wear resistance, resistance to fuels and salt spray, as well as wind and rain erosion, and are inherently flame resistant.

A main problem however is carbon fibers and PEEK matrix exhibit a weak adhesive force at the interface. Strengthening is needed to improve mechanical properties of parts important for space, air, and land vehicles such as bird strike, hailstone, impact of rock, or automobile collision. To overcome this, homogeneous low-voltage electron beam irradiation (HLEBI) is applied to both sides of the sample part. HLEBI has been found to improve the fracture strain of many polymers. ${ }^{6,7)}$ In addition, the irradiation has improved not only the bending fracture strain, ${ }^{8}{ }^{8}$ but also the hardening

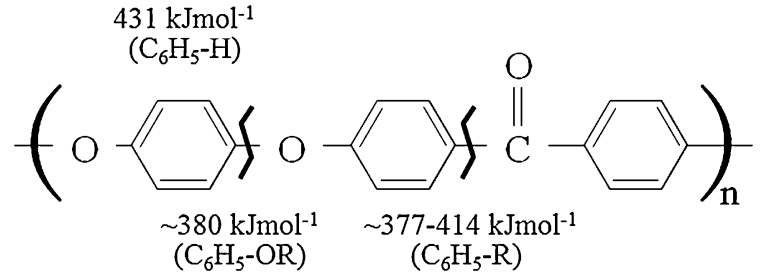

Fig. 1 Schematic illustration of PEEK after electron beam irradiation showing approximate bond dissociation energies and dangling bonds. ${ }^{13,14)}$

modulus, tensile strength, and corresponding strain of carbon fiber. ${ }^{9)}$ To apply to high-speed mover transports, HLEBI also enhances the bending fracture stress, its strain and impact value of thermo-hardened CFRP. ${ }^{9,10}$ Furthermore, HLEBI often enhances the deformation resistivity (elasticity) of polymer $^{11)}$ and carbon fiber. ${ }^{8,9,12)}$ Importantly, HLEBI has been applied to strengthening large parts demonstrating ease of applicability in industrial settings.

The mechanism of HLEBI is it generally cuts the atomic bonding at weak chemical bonding sites as shown for PEEK matrix in Fig. 1 where dangling bonds tend to form at the terminated atoms with low dissociation energies. ${ }^{12)}$

In the PEEK molecular structure bonds with lower dissociation energy include: phenyl groups $\left(\mathrm{C}_{6} \mathrm{H}_{5}-\mathrm{OR}\right.$ : 380 $\left.\mathrm{kJ} \mathrm{mol}^{-1}\right)$ where $\mathrm{R}$ is $-\mathrm{CH}_{3}$; and hexagonal segments $\left(\mathrm{C}_{6} \mathrm{H}_{5}-\right.$ $\mathrm{R})$ where $\mathrm{R}$ of $-\mathrm{CH}_{3},-\mathrm{C}_{2} \mathrm{H}_{5}$, and $-\mathrm{C}_{6} \mathrm{H}_{5}$ are 389,376 , and $418 \mathrm{~kJ} \mathrm{~mol}^{-1}$, respectively. The free-radical hydrogens have higher dissociation energies $\left(\mathrm{H}-\mathrm{C}_{6} \mathrm{H}_{5}: 431 \mathrm{~kJ} \mathrm{~mol}^{-1}\right){ }^{13,14)}$ Dangling bonds have been detected by ESR (electron spin resonance) measurements of PEEK matrix given a 0.43-MGy dose of HLEBI as an increase of peak intensity at $B=$ $322.8 \mathrm{mT}^{15}$ ) Moreover, repulsive force occurs between the negative charges of the outer shell electrons, probably 
inducing compressive stress. ${ }^{15)}$ The HLEBI was found to improve the impact values for fracture of long unidirectional 0 degree carbon fiber CFRP-PEEK at low cumulative probability of $P_{\mathrm{f}}<0.20 .{ }^{15)}$

For the short carbon fiber (SCFRP) PEEK of this study, the compressive stress induced in the matrix by HLEBI is enhanced due to the large interfacial surface area of the $7 \mu \mathrm{m}$ diameter fibers and their short $200 \mu \mathrm{m}$ lengths. The high fiber end density allows for compressive stress in the matrix generated by HLEBI to act in the spaces between fibers enhancing strength over the untreated. The HLEBI is effective in creating stronger fiber/matrix adhesion therefore, the goal of this work is to apply HLEBI to the SCFRP-PEEK.

\section{Experimental}

\subsection{Sample preparation}

Injection-molded short carbon fiber reinforced polyetheretherketone matrix samples SCFRP (PEEK 90CA30) were provided by Victrex ${ }^{\circledR}$. Carbon fiber content was 30 mass $\%$, with diameter, $d \sim 7 \mu \mathrm{m}$, and length, $l \sim 200 \mu \mathrm{m}$, respectively. Volume fractions, $V_{\mathrm{f}}$ were 0.24 and 0.76 for the short carbon fiber and PEEK matrix. Densities, $\rho$ of carbon fiber, PEEK matrix, and the SCFRP composite were 1800, 1300 and $1450 \mathrm{~kg} \mathrm{~m}^{-3}$, respectively. Samples were cut from injection-molded plaques into sizes $l \times b \times t$ of $80 \mathrm{~mm} \times$ $3.0+/-1.0 \mathrm{~mm} \times 3.2+/-0.6 \mathrm{~mm}$ for both bending and impact tests. The processing parameters of the samples are proprietary.

\subsection{Bending test}

In order to evaluate the stiffness, the flexural modulus of the SCFRP-PEEK samples with and without HLEBI were measured using standard testing method for 3-point bending test (IMADA Co., Ltd. DPU-50N/MX-500N/GA-10N) (see JIS K 7074-1998). ${ }^{16)}$ Bending stress $(\sigma)$ and bending strain $(\varepsilon)$ are expressed by the following equations: ${ }^{16)}$

$$
\begin{aligned}
\sigma & =(3 P L) /\left(2 w t^{2}\right) \\
\varepsilon & =(6 t w) / L^{2}
\end{aligned}
$$

Here, $\sigma, P, L, w, t, \varepsilon$, and $d$ are bending stress (MPa), load $(\mathrm{N})$, distance between supporting points $(20 \mathrm{~mm})$, sample width, thickness, bending strain, and amount of deflection $(\mathrm{mm})$, respectively.

The flexural modulus $\left(E_{\mathrm{f}}: \mathrm{GPa}\right)$ is expressed by the following equation. ${ }^{16)}$

$$
E_{\mathrm{f}}=(1 / 4)\left(L^{3} /\left(w t^{3}\right)\right)(P / d)
$$

where maximum slope value $(\mathrm{d} \sigma / \mathrm{d} \varepsilon)_{\max }$ was determined from the slope of stress-strain curves within elastic deformation of $\varepsilon= \pm 8.0 \times 10^{-4}$. The distance between supporting points was $20 \mathrm{~mm}$. The testing speed was $6.5 \mathrm{~mm} / \mathrm{min}$.

\subsection{Charpy impact tests}

Typically, to screen aircraft materials such as long-fiber quasiisotropic laminates and weaves for resistance against birdstrike, hailstone, or volcanic rock, damage by a hemispherical impactor is initiated as a point force on the center of a square or rectangular specimen $\sim 70$ to $150 \mathrm{~mm}^{2}$ by slow point force, ${ }^{13)}$ drop tower, or projectile. ${ }^{17-20)}$ Initiation of damage in the form of delamination is usually assessed by non-destructive evaluation (NDE) such as an ultrasonic sensor. This is usually followed by compression after impact (CAI) tests to compare integrity and safety level of candidate materials after impact. However, the material under investigation is a non-laminate short-fiber SCFRP. Therefore, we employ Charpy impact test which utilizes a drop-weight pendulum and evaluates the impact absorption characteristics and relative impact toughness of materials often used in quality control (QC) applications employed as an inexpensive and fast way to estimate reaction to higher velocity impact. We do not claim the Charpy impact test to be a replacement for point-force tests followed by CAI. But we assert Charpy impact may be used as a preliminary method to screen for candidate materials for later evaluation by projectile and CAI.

The Charpy impact testing device is calibrated for air friction and effect of air temperature and humidity on the swing and pivot of the pendulum. Therefore the velocity, $v\left(\mathrm{~m} \mathrm{~s}^{-1}\right)$ and kinetic energy, $K E(\mathrm{~J})$ hitting the sample are assumed to be approximately constant similar to comparing projectiles in a point impact test hitting the composite surface at constant $v$ and $K E$. Thus, when the Charpy impact test impact velocity, $v$ hitting the sample is calculated as: ${ }^{21)}$

$$
v=[2 g R(1-\cos \alpha)]^{0.5}
$$

where $g$ is gravitational constant $\left(9.8 \mathrm{~m} \mathrm{~s}^{-2}\right), R$ is length (m) of hammer weight point from rolling center $(0.21 \mathrm{~m})$, and $\alpha$ is start angle before impact $\left(2.3\right.$ Radians, $\left.132^{\circ}\right)$, then $v$ of the hammer hitting the specimen is $\sim 1.74 \mathrm{~m} \mathrm{~s}^{-1}(\sim 3.89 \mathrm{mi} / \mathrm{h})$. Potential energy $(P E)(\mathrm{J})$ of impact is: ${ }^{21)}$

$$
P E=R(1-\cos \alpha) F
$$

where $F$ is the measured supporting force $(\mathrm{N})$ exerted by the pendulum in the horizontal position. $P E$ is assumed to be equivalent to the $K E$ in the horizontal vector, $0.5 m v^{2}$, or $1.30 \mathrm{~J}\left(1.3 \times 10^{-3} \mathrm{~kJ}\right)$. The surface area $A$ hitting the sample of the $1.5 \mathrm{~mm}$ diameter hemispherically-shaped impactor is small so $K E / A$ is large.

In order to evaluate the impact fracture toughness, the Charpy impact values of the SCFRP-PEEK with and without HLEBI were measured using a standard impact fracture energy measurement system (Shimadzu Corporation No. 51735) (JIS K 7077). ${ }^{10,12,15)}$ The impact fracture energy $(E)$ is expressed by the following equation: ${ }^{10,12,15)}$

$$
\begin{aligned}
E= & W R[(\cos \beta-\cos \alpha) \\
& \left.-\left(\cos \alpha^{\prime}-\cos \alpha\right)(\alpha+\beta) /\left(\alpha-\alpha^{\prime}\right)\right]
\end{aligned}
$$

Here, $E, W, R, \beta, \alpha$ and $\alpha^{\prime}$ are impact fracture energy $(\mathrm{kJ})$, hammer mass $(\mathrm{kg})$, length $(\mathrm{m})$ of hammer weight point from rolling center, maximum angle after impact (Radians), start angle before impact and the maximum angle of the blank test, respectively. The Charpy impact value $\left(a_{\mathrm{uc}}: \mathrm{kJ} \mathrm{m}^{-2}\right)$ is expressed by the following equation:

$$
a_{\mathrm{uc}}=E /(w t)
$$

Here, $E, w[3.0+/-1.0 \mathrm{~mm}]$ and $t[3.2+/-0.6 \mathrm{~mm}]$ are impact fracture energy $(\mathrm{J})$, sample width $(\mathrm{mm})$ and sample thickness $(\mathrm{mm})$, respectively. The distance between supporting points was $40 \mathrm{~mm}$. 


\subsection{Homogeneous low-voltage electron beam irradiation (HLEBI)}

HLEBI was performed using an electron-curtain processor (Type CB175/15/180L, Energy Science Inc., Woburn, MA). ${ }^{22-24)}$ After specimens were cut from the CFRTP sheet, they were homogeneously irradiated with the electron beam through a titanium thin film window attached to the vacuum chamber, $240 \mathrm{~mm}$ in diameter. A tungsten filament in the vacuum was used to generate the electron beam at the low energy (acceleration potential, $V: \mathrm{MeV}$ ), of $0.17 \mathrm{MeV}$ and irradiating current density $\left(J: \mathrm{Am}^{-2}\right)$ of $0.089 \mathrm{Am}^{-2}$. The distance between sample and window was $35 \mathrm{~mm}$. Although electron beam generation was done in a vacuum, to prevent oxidation the samples were kept in a protective $1.0 \mathrm{~atm}$ of nitrogen gas with a residual concentration of oxygen below $0.030 \%$. The $\mathrm{N}_{2}$ flow rate was $1.5 \mathrm{Ls}^{-1}$ at $0.10 \mathrm{MPa} \mathrm{N}_{2}$ pressure. The samples in the aluminum plate tray $(0.15 \times 0.15 \mathrm{~m})$ were transported on a conveyor at a speed of $10 \mathrm{mmin}^{-1}$. The sheet electron beam irradiation was applied intermittently, one sweep going one way was $0.043 \mathrm{MGy}\left(\mathrm{kJ} \mathrm{g}^{-1}\right)$ with a gap interval of $30 \mathrm{~s}$ between each sweep. The $0.043 \mathrm{MGy}$ was applied for only a short time $(0.23 \mathrm{~s})$ to avoid excessive heating of the sample; the temperature of the sample surface remained below $323 \mathrm{~K}$ just after irradiation. Total irradiation dose, $D$ (MGy) is determined from the number of irradiation sweeps $(N)$, current, $I(\mathrm{~mA})$, and conveyor speed, $S\left(\mathrm{mmin}^{-1}\right):^{24)}$

$$
D=0.216(I / S) / N
$$

Absorbed dose was corrected by using FWT nylon dosimeter of RCD radiometer film (FWT-60-00) with irradiation reader (FWT-92D) from Far West Technology, Inc. 330-D South Kellogg Goleta, California 93117, USA. Since estimated penetration depth $D_{\mathrm{p}}$ of HLEBI is calculated to be $189+/-37 \mu \mathrm{m}(3-11 \%$ of the thickness) into both side surfaces of the short-fiber SCFRP-PEEK samples with $3.0+/-1.0 \mathrm{~mm}$ thickness, it is expected that the HLEBI can improve the mechanical properties of flexural modulus and impact value of the SCFRP-PEEK.

\section{Results}

\subsection{3-point bending}

Figure 2 shows bending stress-strain curves of the SCFRP-PEEK with and without HLEBI. Although the higher $0.86 \mathrm{MGy}$ dose of HLEBI reduces the slope $(\mathrm{d} \sigma / \mathrm{d} \varepsilon)$, results show the slope is raised by the lower $0.43 \mathrm{MGy}$ dose.

Evaluating the cumulative probability, $P_{\mathrm{x}}$ as a distribution function for a given data set is a convenient method of quantitatively analyzing experimental values for reliability and often applied in quality control. For example, $P_{\mathrm{E}}$ for bending modulus is expressed in eq. (9) which is a generalized form of the median-rank method. ${ }^{25,26)}$

$$
P_{\mathrm{E}}=(i-0.3) /\left(N_{\mathrm{s}}+0.4\right)
$$

Here $N_{\mathrm{s}}$ and $i$ are total number of samples $\left(N_{\mathrm{s}}=11\right)$, and rank order integer of the property, in this case bending modulus $E_{\mathrm{f}}$ of each sample, respectively, where $i$ is from low to high rank. When the $i$ values are 1, 6, and 11, their corresponding $E_{\mathrm{f}}$ values are $0.06,0.50$ and 0.94 , respectively.

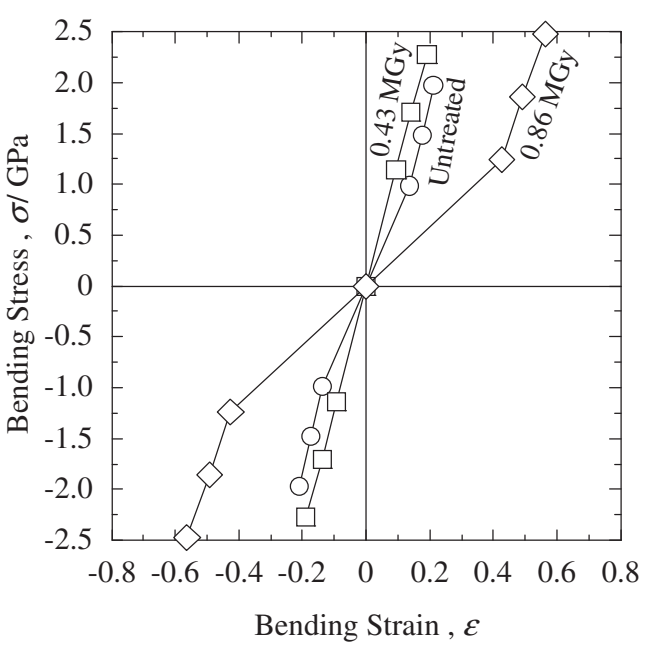

Fig. 2 Bending stress-bending strain curves at $P_{\mathrm{E}}$ of 0.50 for the SCFRPPEEK with and without HLEBI at dose 0.43 and $0.86 \mathrm{MGy}$.

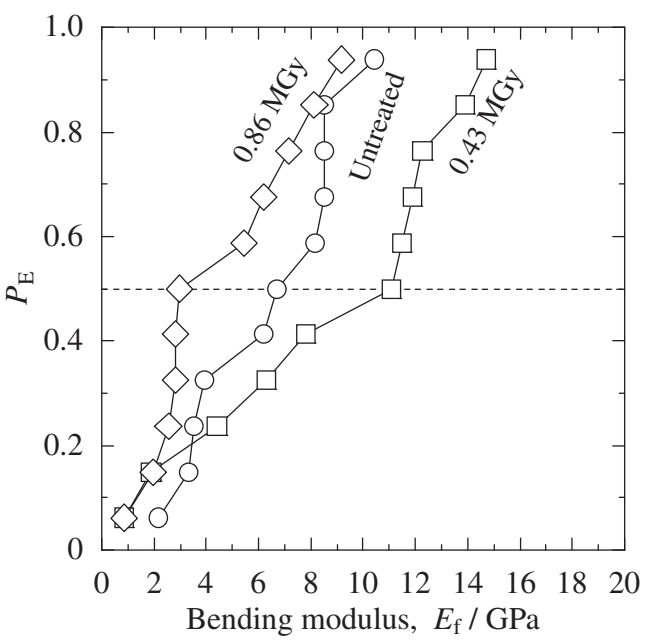

Fig. 3 Relationships between bending modulus $\left(E_{\mathrm{f}}\right)$ and its cumulative probability $\left(P_{\mathrm{E}}\right)$ for untreated, 0.43 and $0.86 \mathrm{MGy}$ HLEBI-treated shortfiber SCFRP-PEEK.

Figure 3 shows bending modulus $\left(E_{\mathrm{f}}\right)$ as a function of $P_{\mathrm{E}}$ for untreated, 0.43 and $0.86 \mathrm{MGy}$ HLEBI dose samples.

Experimental results in Fig. 3 show although the 0.43 MGy HLEBI reduces the bending modulus $\left(E_{\mathrm{f}}\right)$ values below $P_{\mathrm{E}}$ of 0.20 , the $0.43 \mathrm{MGy}$ HLEBI remarkably enhances the $E_{\mathrm{f}}$ $65.5 \%$ from 6.7 to $11.1 \mathrm{GPa}$ at median-ranked cumulative probability $\left(P_{\mathrm{E}}=0.50\right)$ over the untreated. At $P_{\mathrm{E}}=0.85$ the $E_{\mathrm{f}}$ was enhanced $63.4 \%$ from 8.52 to $13.92 \mathrm{GPa}$. The 0.43 MGy HLEBI apparently enhances the $E_{\mathrm{f}}$ over the untreated at all $P_{\mathrm{f}}>0.20$. Overall the average $E_{\mathrm{f}}$ was raised $38.1 \%$ from 6.36 to $8.78 \mathrm{GPa}$.

\subsection{Charpy impact}

When $N_{\mathrm{s}}^{\prime}$ and $i^{\prime}$ are total number of Charpy impact samples and rank order integer, the cumulative probability for impact fracture, $P_{\mathrm{f}}$ is expressed in eq. $(10)^{25,26)}$

$$
P_{\mathrm{f}}=\left(i^{\prime}-0.3\right) /\left(N_{\mathrm{s}}^{\prime}+0.4\right)
$$

whose experimental values are shown in Fig. 4. The application of the $0.43 \mathrm{MGy}$ HLEBI to the short-fiber 


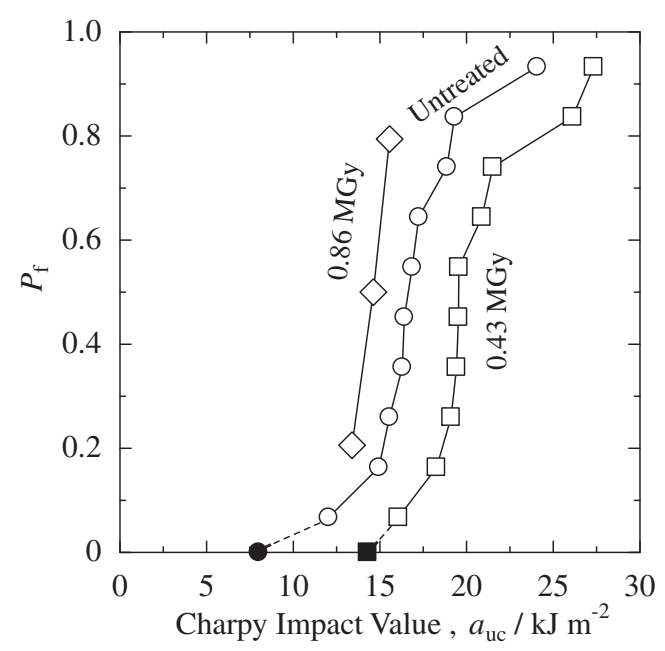

Fig. 4 Relationships between Charpy impact value $\left(a_{\mathrm{uc}}\right)$ and its cumulative probability $\left(P_{\mathrm{f}}\right)$ for untreated, 0.43 and $0.86 \mathrm{MGy}$ HLEBI-treated SCFRPPEEK, together with the lowest impact value $\left(a_{\mathrm{s}}\right)$. The iterated $a_{\mathrm{s}}$ for $P_{\mathrm{f}}=0$ are included.

SCFRP-PEEK samples apparently improved Charpy impact value, $a_{\mathrm{uc}}$ over the untreated at all $P_{\mathrm{f}}$. Moreover, at median- $P_{\mathrm{f}}$ of 0.50 the $0.43 \mathrm{MGy}$ increased the impact values $17.5 \%$ from 16.6 to $19.5 \mathrm{~kJ} \mathrm{~m}^{-2}$. Overall, the $0.43 \mathrm{MGy}$ HLEBI increased the average $a_{\mathrm{uc}} 21.1 \%$ over the untreated samples from 17.1 to $20.8 \mathrm{~kJ} \mathrm{~m}^{-2}$.

\section{Discussion}

\subsection{Effect of EB irradiation on the lowest impact $\left(a_{\mathrm{s}}\right)$ value}

If the statistical equation is assumed to be applicable to the measured Charpy impact value $\left(a_{\mathrm{uc}}\right)$, the $P_{\mathrm{f}}$ depends on the risk of rupture $\left(\left[a_{\mathrm{uc}}-a_{\mathrm{s}}\right] / a_{\mathrm{III}}\right) .^{27,28)}$

$$
P_{\mathrm{f}}=1-\exp \left[-\left(\left[a_{\mathrm{uc}}-a_{\mathrm{s}}\right] / a_{\mathrm{III}}\right)^{m}\right]
$$

In predicting the required impact value for new structural materials, the lowest impact value $\left(a_{\mathrm{s}}\right)$, the 3-parameter Weibull coefficient $(m)$ and the $\left(a_{\mathrm{III}}\right)$ which are both constants from their respective data sets are the key parameters. While the $a_{\mathrm{III}}$ is determined when the term $\left(\ln \left[-\ln \left(1-P_{\mathrm{f}}\right)\right]\right)$ is zero, the $a_{\mathrm{s}}$ value is defined as the $a_{\mathrm{uc}}$ value when $P_{\mathrm{f}}=0$ and represents the statistically lowest possible impact value for safety considerations and is used for quality control.

Figure 5 shows iteration of the potential lowest impact value ( ${ }^{\mathrm{e}} a_{\mathrm{s}}$ ) to obtain the lowest impact value, $a_{\mathrm{s}}$ at the maximum correlation coefficient, $F$ (arrows) from the linear logarithmic form (see Fig. 6) of eq. (11) showing applying the $0.43 \mathrm{MGy}$ HLEBI significantly raises the $a_{\mathrm{s}} 80.0 \%$ from 8.0 to $14.4 \mathrm{~kJ} \mathrm{~m}^{-2}$ (see Fig. 4 ).

\subsection{Effects of HLEBI on bending modulus and Charpy impact values}

From conventional X-ray diffraction patterns (XRD) of the carbon fiber before and after EB irradiation, remarkable differences cannot be observed therefore, the HLEBI does not appear to change crystal structure. However, dangling bonds are reported to spontaneously exist in carbon fiber before and after $\mathrm{HLEBI}^{15}$ ) by electron spin resonance (ESR) measure-

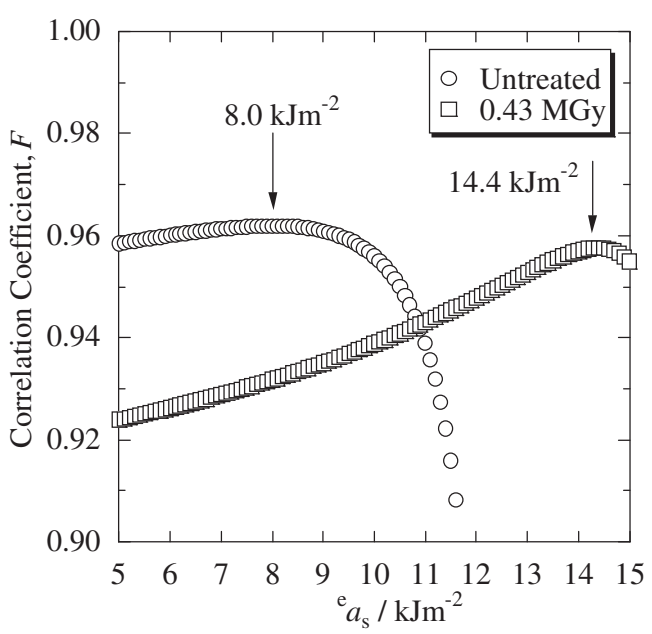

Fig. 5 Changes in correlation coefficient $(F)$ against the potential $a_{\mathrm{s}}$ value ( ${ }^{\mathrm{a}} a_{\mathrm{s}}$ ) for SCFRP-PEEK.

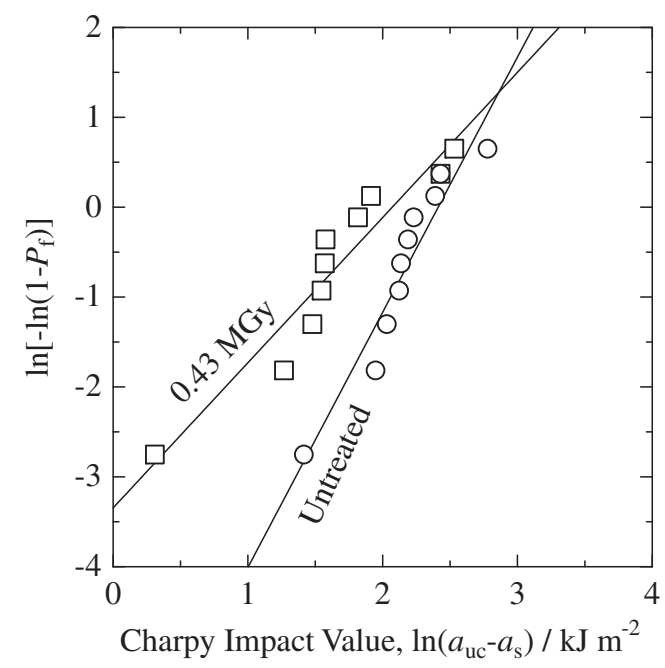

Fig. 6 Liner relationships between $\ln \left(a_{\mathrm{uc}}-a_{\mathrm{s}}\right)$ and $\ln \left[-\ln \left(1-P_{\mathrm{f}}\right)\right]$ of CFRTP (PEEK).

ments. ESR is utilized to detect unpaired electrons by their spins $\left(m_{\mathrm{s}}=+/-1 / 2\right)$ since electrons have a magnetic moment and spin quantum number. The unpaired electrons' magnetic moments either align themselves parallel or antiparallel to an induced magnetic field producing a peak at a particular magnetic field, $B$.

Spontaneous dangling bond density of carbon fibers measured by ESR before irradiation is reported to be $1.2 \times$ $10^{17}$ spins $\mathrm{mm}^{-3}{ }^{15)}$ Applying 0.43 MGy dose of HLEBI has been found to decrease the dangling bond density in carbon fiber at $B=\sim 322.4 \mathrm{mT}$. This annihilation of dangling bonds of carbon fiber has been found to enhance the tensile fracture stress and fracture strain of bending tests. ${ }^{8,9,12)}$

Moreover, dangling bonds have been detected by ESR in PEEK matrix irradiated by $0.43-\mathrm{MGy}$ dose of HLEBI as an increase of peak intensity at $B=322.8 \mathrm{mT}^{15}$ ) The dangling bond density of PEEK samples before irradiation is reported to be $1.5 \times 10^{12}$ spins $\mathrm{mm}^{-3}$, ${ }^{26)}$ about 5 orders of magnitude lower than carbon fiber. The HLEBI was found to improve the impact values of long unidirectional 0 degree carbon fiber CFRP-PEEK at low cumulative probability of $P_{\mathrm{f}}<0.20$. The 
enhancement was attributed to generation of repulsive force between the negative charges of the outer shell electrons, inducing compressive stress within the matrix on the carbon fibers as well as strengthening of the carbon fibers. ${ }^{15)}$

Interestingly in CFRP-PEEK composite, experimental results showed ESR signals have not been observed in either untreated or HLEBI-treated. This may be due to interference between the two peaks which reside close to each other cancelling each other out: HLEBI lowers the peak intensity of carbon fiber at $\sim 322.4 \mathrm{mT}$, while raising the peak intensity of PEEK matrix which occurs at $\sim 322.8 \mathrm{mT}$. Moreover, difference in binding energies of the dangling bonds can cause electrons to migrate between the carbon fiber and PEEK matrix as they are energized maintaining an overall charge that enhances strength and fiber/matrix coupling undetectable by the ESR in the composite.

\subsection{Penetration depth, $D_{\mathrm{p}}$ calculation compared with reported experimental data of HLEBI into layered PEEK matrix}

Penetration depth of the electron beam is one of the important factors for dominating productivity and part thickness choice to apply for practical use. Based on the sample density, $\rho\left(\mathrm{kg} \mathrm{m}^{-3}\right)$ and irradiation voltage, $V(\mathrm{keV})$, the EB-irradiation depth, $D_{\mathrm{p}}(\mu \mathrm{m})$ can be obtained by assumptions of Christenhusz and Reimer ${ }^{29)}$

$$
D_{\mathrm{p}}=66.7 \mathrm{~V}^{5 / 3} / \rho
$$

The surface electrical potential, $(130 \mathrm{keV})$ can be determined from the electrical potential $(170 \mathrm{keV})$ the $10 \mu \mathrm{m}$ Ti thickness $\left(\rho=4540 \mathrm{~kg} \mathrm{~m}^{-3}\right)$ and the $30 \mathrm{~mm}$ distance between the sample and window in the $\mathrm{N}_{2(\mathrm{~g})}$ atmosphere $\left(1.13 \mathrm{~kg} \mathrm{~m}^{-3}\right)$. Since the densities of carbon fiber and PEEK are $\rho=1,300$ and $1,800 \mathrm{~kg} \mathrm{~m}^{-3}$, and that calculated for the 0.24 fiber $V_{\mathrm{f}}$ SCFRP-PEEK samples is $1,450 \mathrm{~kg} \mathrm{~m}^{-3}$ the HLEBI depths, $D_{\mathrm{p}}$ by the Christenhusz and Reimer assumption for the SCFRP-PEEK, carbon fiber and PEEK matrix estimated from eq. (12) are 153,123 and $170 \mu \mathrm{m}$, respectively.

Another common practice is the assumption by Libby ${ }^{30}$ which relates $D_{\mathrm{p}}$ to mass thickness, $l_{\mathrm{o}}\left(\mathrm{g} \mathrm{m}^{-2}\right)$ and irradiation voltage $(170 \mathrm{keV})$. Since the electron beam travels through the Ti foil $\left(l_{\mathrm{o}}=18 \mathrm{~g} \mathrm{~m}^{-2}\right)$ and $\mathrm{N}_{2(\mathrm{~g})}\left(l_{\mathrm{o}}=1.5 \mathrm{~g} \mathrm{~m}^{-2}\right)$ before contacting the sample, their mass thicknesses, $l_{\mathrm{o}}$ reduce the number of electrons that would hit the sample, therefore $l_{\mathrm{o}}$ of the sample is $0.33 \mathrm{~g} \mathrm{~m}^{-2}$ by eq. (13):

$$
l_{\mathrm{o}}=E^{5 / 3} / 150
$$

Therefore the voltage at the sample surface, $E$ is calculated by:

$$
E=\left(150 l_{\mathrm{o}}\right)^{3 / 5}
$$

with $E=164 \mathrm{keV}$. Hence, by using the assumption of Libby $^{30)} D_{\mathrm{p}}$ for SCFRP-PEEK, carbon fiber and PEEK matrix are 226, 182 and $252 \mu \mathrm{m}$.

Using both assumptions therefore, estimated irradiated depth of the SCFRP-PEEK is $189+/-37 \mu \mathrm{m}$ at both side surfaces, or $3-11 \%$ of sample thickness. ${ }^{29,30)}$ From this it is expected that the HLEBI improves the mechanical properties of flexural modulus and impact value of the SCFRPPEEK.
In order to confirm the penetration depth $\left(D_{\mathrm{p}}\right), 280 \mu \mathrm{m}$ thickness PEEK sheet laminated by eleven PEEK films with $25 \mu \mathrm{m}$ thickness has been irradiated with $0.30 \mathrm{MGy}$ HLEBI. $^{26)}$ Dangling bond density was subsequently evaluated by ESR spectra of each PEEK layer separately. Although the dangling bond density reported for PEEK before HLEBI irradiation is $1.5 \times 10^{12}$ spins $\mathrm{mm}^{-3}$, in 0.30 MGy-irradiated PEEK the increased dangling bond density between $2.0 \times 10^{12}$ and $5.0 \times 10^{12}$ spins $\mathrm{mm}^{-3}$ is observed from the surface to $D_{\mathrm{p}}=250 \mu \mathrm{m}$. From 250 to $280 \mu \mathrm{m}$ is the "drastic reduction zone" where the dangling bond density

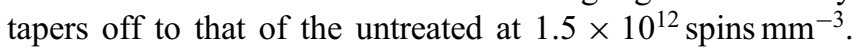
The estimated penetration depth, $D_{\mathrm{p}}$ of irradiated PEEK by using the assumption of Libby ${ }^{30}$ of $252 \mu \mathrm{m}$ closely agrees with the experimental value of $250 \mu \mathrm{m}-D_{\mathrm{p}}$.

The near-surface mechanical properties, therefore will differ from the bulk properties. When the experimental $D_{\mathrm{p}}$ and drastic reduction zone of PEEK matrix $(30 \mu \mathrm{m})$ is assumed to be approximately equal to that of the SCFRP-PEEK, the $[3.0+/-1.0 \mathrm{~mm}]$ thick samples have a 5-layer structure of HLEBI influence: irradiation zone skins $(189+/-37 \mu \mathrm{m})$; middle drastic reduction zone shells $(30$ $\mu \mathrm{m})$; surrounding an irradiation-free zone core $(2,830+/-$ $698 \mu \mathrm{m})$.

\subsection{Scanning electron microscopy (SEM)}

Figures 7 to 10 show scanning electron micrographs (SEM) of untreated and $0.43 \mathrm{MGy}$ treated SCFRP-PEEK fracture surfaces after Charpy impact tests showing increased matrix adhering to fibers and in between fibers in the HELBI samples. The untreated sample in Fig. 7 shows evidence of fiber pullout in the form of holes and numerous fibers sticking out of the matrix. The matrix itself appears to have been separated fairly easily without peeling. At higher magnification, Fig. 8 shows the exposed fibers at the fracture surface.

On the other hand, the $0.43 \mathrm{MGy}$ irradiated sample in Fig. 9 shows much less exposed fiber surfaces than that of the untreated with considerable peeling-like fracture of the PEEK matrix. This peeling-like fracture may take more energy than the easily separated. The fracture surface of the 0.43 MGy sample appears flatter than that of the untreated.

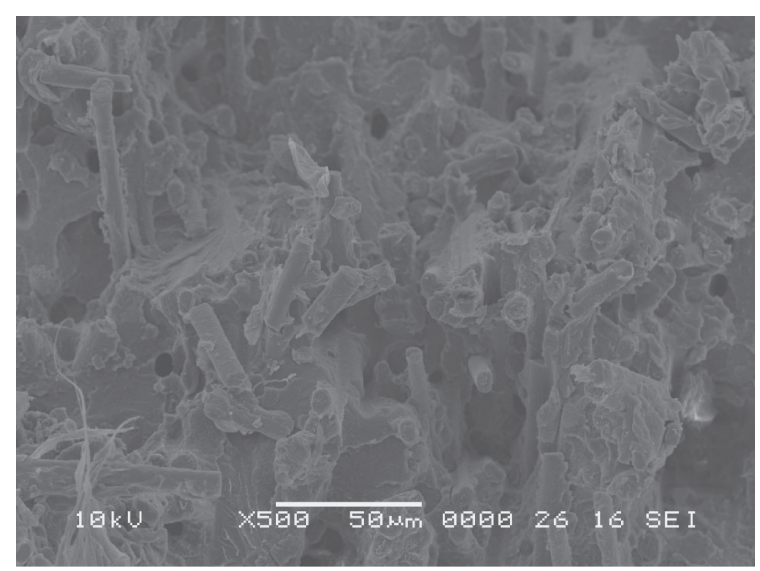

Fig. 7 Scanning electron micrograph (SEM) of untreated SCFRP-PEEK fracture surface at the crack front. 


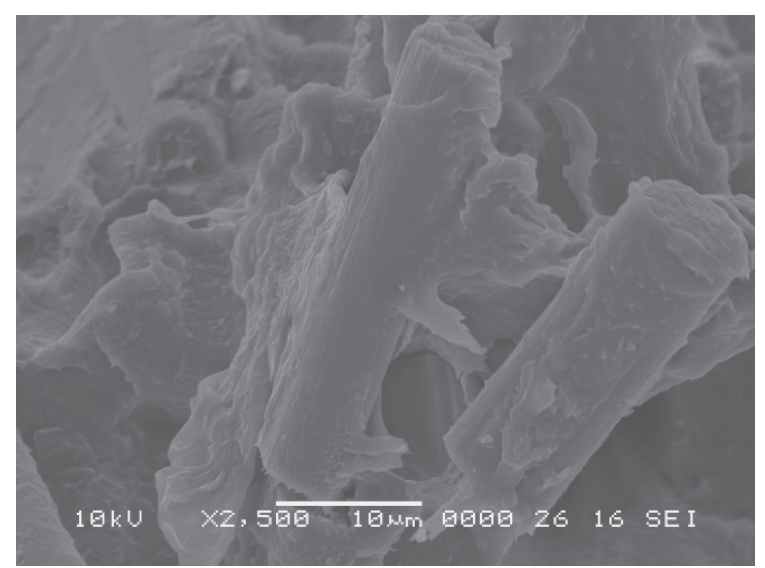

Fig. 8 Scanning electron micrograph (SEM) of untreated SCFRP-PEEK at higher magnification.

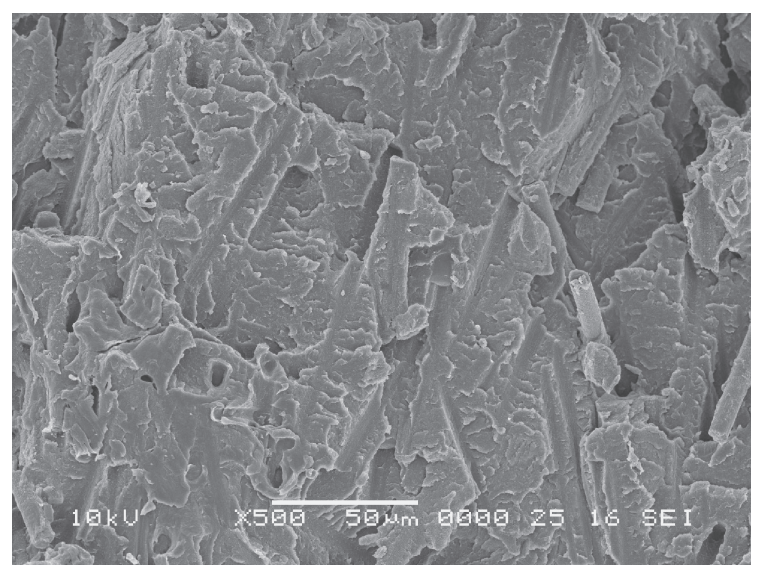

Fig. 9 Scanning electron micrograph (SEM) of 0.43 MGy HLEBI treated SCFRP-PEEK fracture surface at the crack front.

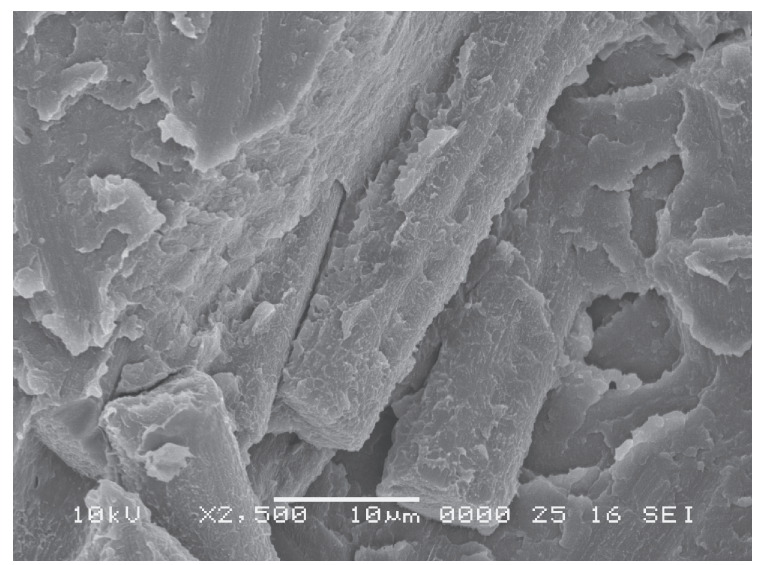

Fig. 10 Scanning electron micrograph (SEM) of 0.43 MGy HLEBI treated SCFRP-PEEK at higher magnification.

At higher magnification, the $0.43 \mathrm{MGy}$ irradiated sample of Fig. 10 shows more matrix sticking to the fibers and more matrix being held between fibers than the untreated increasing pullout resistance. Increased matrix adhering to fibers by HLEBI was also found in unsaturated polyester GFRP-BMC increasing impact strength. ${ }^{23)}$ In the SCFRPPEEK the HLEBI appears to assist in strengthening the weak bonding between the carbon fiber and PEEK matrix improving its mechanical properties.

\section{Conclusions}

Experimental results show applying homogeneous lowvoltage electron beam irradiation (HLEBI) to be a viable method to increase the weak bonding between carbon fiber and PEEK matrix typically found in CFRP-PEEK composites.

(1) A dose of 0.43 MGy HLEBI applied to both specimen side surfaces improved not only the bending modulus $\left(E_{\mathrm{f}}\right) \quad 65.5 \%$ at median-rank cumulative probability $\left(P_{\mathrm{E}}=0.50\right)$ from 6.7 to $11.1 \mathrm{GPa}$, but also Charpy impact value $\left(a_{\mathrm{uc}}\right) 17.5 \%$ at median- $P_{\mathrm{f}}=0.50$ from 16.6 to $19.5 \mathrm{~kJ} \mathrm{~m}^{-2}$ of the short-fiber injection-molded SCFRP-PEEK.

(2) Moreover, the statistically lowest Charpy impact value $a_{\mathrm{s}}$ at $P_{\mathrm{f}}=0$ calculated by 3-parameter Weibull equation was increased $80.0 \%$ from 8.0 to $14.4 \mathrm{~kJ} \mathrm{~m}^{-2}$ by the 0.43 MGy HLEBI.

(3) While penetration depth, $D_{\mathrm{p}}$ of the HLEBI was calculated to be $3-11 \%$ into both side surfaces, SEM results of the $0.43 \mathrm{MGy}$ HLEBI samples showed increased matrix sticking to the fibers and more matrix being held between fibers than the untreated increasing pullout resistance. The HLEBI appears to be a promising method to assist in strengthening the typically weak bonding between the carbon fiber and PEEK matrix to improve mechanical properties of carbon fiber reinforced PEEK composites.

\section{Acknowledgements}

The authors would like to express their sincere gratitude to Dr. Keisuke Iwata of Tokai University for the sample preparation and his useful help.

This work was partly supported by the JSPS Core-to-Core Program, A. Advanced Research Networks, "International research core on smart layered materials and structures for energy saving".

\section{REFERENCES}

1) D. K. Thomas: Plastics Rubber Int. 8 (1983) 53-57.

2) M. B. Dowell: Plastics Eng. 33 (1977) 31-32.

3) H. Kosuda and K. Nakama: Kagaku kogyo-ajia 28 (1981) No. 12, p. 28.

4) B. Sivasankar: Engineering Chemistry, (Tata McGraw-Hill, New Delhi, 2008).

5) M. Makihara: Japan Plastics 53 (2002) pp. 119-122.

6) T. Takahashi, T. Morishita and Y. Nishi: J. Jpn. Inst. Metals 69 (1988) 2753-2760.

7) A. Mizutani and Y. Nishi: Mater. Trans. 44 (2003) 1857-1860.

8) Y. Nishi, T. Toriyama, K. Oguri, A. Tonegawa and K. Takayama: J. Mater. Res. 16 (2001) 1632-1635.

9) Y. Nishi, A. Mizutani, A. Kimura, T. Toriyama, K. Oguri and A. Tonegawa: J. Mater. Sci. 38 (2003) 89-92.

10) Y. Nishi, K. Inoue and M. Salvia: Mater. Trans. 47 (2006) 2846-2851.

11) H. Sato, K. Iwata, A. Tonegawa and Y. Nishi: J. Jpn. Inst. Metals 72 (2008) 526-531.

12) Y. Nishi, A. Mizutani and N. Uchida: J. Thermoplast. Compos. Mater. 17 (2004) 289-302.

13) A. James and M. Lord: Macmillan's Chemical and Physical Data, (The Macmillan Press, Ltd., London and Basingstoke, 1992) p. 485.

14) A. Gordon and R. Ford: The Chemist's Companion: A Handbook of Practical Data, Techniques, and References, (Wiley Interscience Publication, New York, 1972) p. 113. 
15) Y. Nishi, H. Takei, K. Iwata, M. Salvia and A. Vautrin: Mater Trans. 50 (2009) 2826-2832.

16) Japanese Industrial Standards Committee: JIS K7074 (1998).

17) K. Imielińska, L. Guillaumat, R. Wojtyra and M. Castaings: Compos Part B 39 (2008) 1034-1041.

18) A. S. Vaidya, U. K. Vaidya and N. Uddin: Mater. Sci. Eng. A 472 (2008) 52-58.

19) O. S. David-West, D. H. Nash and W. M. Banks: Compos. Struct. 83 (2008) 247-258

20) L. Aktay, A. F. Johnson and M. Holzapfel: Comput. Mater. Sci. 32 (2005) 252-260

21) J. D. Splett, H. K. Iyer, C.-M. Wang and C. N. McCowan: National Institute of Standards and Technology (NIST) Recommended Practice Guide, Computing Uncertainty for Charpy Impact Test, Machine Test Results; Special Publication 960-18, (US Department of Commerce: Boulder, Colorado, 2008) pp. 27-29.

22) K. Oguri, N. Iwataka, A. Tonegawa, Y. Hirose, K. Takayama and Y.
Nishi: J. Mater. Res. 16 (2001) 553-557.

23) M. Faudree, Y. Nishi and M. Gruskiewicz: Mater. Trans. 53 (2012) 1412-1419.

24) H. Takei, K. Iwata, M. Salvia, A. Vautrin and Y. Nishi: Mater. Trans. 51 (2010) 2259-2265.

25) K. Komai, K. Minoshima and K. Tanaka: Trans. Jpn. Soc. Mech. Eng. A 64 (1998) 2300-2307.

26) H. Takei, M. Salvia, A. Vautrin, A. Tonegawa and Y. Nishi: Mater. Trans. 52 (2011) 734-739.

27) T. Nishida and E. Yasuda: Evaluation of Dynamic Properties of Ceramics Ceramics no Rikigaku Tokusei hyouka, (Nikkan Kogyou Shimbun Sha, Tokyo, 1986) (in Japanese).

28) W. Weibull: Ingeniörs vetenskaps akademien, nr. 151, (Generalstabens litografiska anstalts förlag, Stockholm, 1939) p. 1214.

29) R. Christenhusz and L. Reimer: Z. Angew. Phys. 23 (1967) 396-404.

30) W. F. Libby: Anal. Chem. 19 (1947) 2-6. 